\title{
Acute Stress Enhances Associative Learning via Dopamine Signaling in the Ventral Lateral Striatum
}

\author{
${ }^{\circledR C}$ Claire E. Stelly, Sean C. Tritley, Yousef Rafati, and ${ }^{\circledR}$ Matthew J. Wanat \\ Neurosciences Institute and Department of Biology, University of Texas at San Antonio, San Antonio, Texas 78249
}

Acute stress transiently increases vigilance, enhancing the detection of salient stimuli in one's environment. This increased perceptual sensitivity is thought to promote the association of rewarding outcomes with relevant cues. The mesolimbic dopamine system is critical for learning cue-reward associations. Dopamine levels in the ventral striatum are elevated following exposure to stress. Together, this suggests that the mesolimbic dopamine system could mediate the influence of acute stress on cue-reward learning. To address this possibility, we examined how a single stressful experience influenced learning in an appetitive pavlovian conditioning task. Male rats underwent an episode of restraint prior to the first conditioning session. This acute stress treatment augmented conditioned responding in subsequent sessions. Voltammetry recordings of mesolimbic dopamine levels demonstrated that acute stress selectively increased reward-evoked dopamine release in the ventral lateral striatum (VLS), but not in the ventral medial striatum. Antagonizing dopamine receptors in the VLS blocked the stressinduced enhancement of conditioned responding. Collectively, these findings illustrate that stress engages dopamine signaling in the VLS to facilitate appetitive learning.

Key words: dopamine; learning; stress; ventral striatum

Significance Statement

Acute stress influences learning about aversive and rewarding outcomes. Dopamine neurons are sensitive to stress and critical for reward learning. However, it is unclear whether stress regulates reward learning via dopamine signaling. Using fast-scan cyclic voltammetry as rats underwent pavlovian conditioning, we demonstrate that a single stressful experience increases reward-evoked dopamine release in the ventral lateral striatum. This enhanced dopamine signal accompanies a long-lasting increase in conditioned behavioral responding. These findings highlight that the ventral lateral striatum is a node for mediating the effect of stress on reward processing.

\section{Introduction}

Acute stress triggers a transient state of increased vigilance. This heightened awareness of one's surroundings reflects activation of the "salience network," a large-scale brain network for detecting and attending to stimuli that are potentially harmful or beneficial (Seeley et al., 2007; Hermans et al., 2011, 2014; Clemens et al., 2017; Schwabe, 2017). Increased stimulus salience is theorized to facilitate associative learning (Rescorla and Wagner, 1972; Mackintosh, 1975). As stress increases salience, associative learning should be enhanced accordingly. Consistent with this idea, stress promotes conditioned responding to aversive cues (Wilson et al., 1975; Shors et al., 1992; Shors, 2001; Rau and Fanselow,

\footnotetext{
Received Dec. 18, 2019; revised Mar. 17, 2020; accepted Apr. 8, 2020.

Author contributions: M.J.W. and C.E.S. designed the experiments; C.E.S., S.C.T., and Y.R. performed the experiments; C.E.S., S.C.T., and Y.R. analyzed the data; C.E.S. and M.J.W. wrote the paper.

This work was supported by National Institutes of Health Grants DA-033386 and DA-042362 to M.J.W. We thank Idaira Oliva Padron for pilot studies and Merridee Lefner for critical input on the manuscript.

The authors declare no competing financial interests.

Correspondence should be addressed to Matthew J. Wanat at Matthew.wanat@utsa.edu.

https://doi.org/10.1523/JNEUROSCI.3003-19.2020

Copyright $\odot 2020$ the authors
}

2009; Goodman et al., 2018). While stress facilitates learning to associate contextual cues with drug rewards (Montagud-Romero et al., 2015; Tovar-Diaz et al., 2018), it is unclear whether acute stress additionally enhances conditioning with natural rewards.

Phasic dopamine release in the ventral striatum is essential for learning to associate cues with rewarding outcomes (Tsai et al., 2009; Steinberg et al., 2013; Darvas et al., 2014; Chang et al., 2016; Saunders et al., 2018). The mesolimbic dopamine system is also sensitive to stress, as dopamine levels in the ventral striatum are modulated during and after exposure to stressors (Abercrombie et al., 1989; Puglisi-Allegra et al., 1991; Kalivas and Duffy, 1995; Tidey and Miczek, 1996; Anstrom et al., 2009; Valenti et al., 2011). However, it is not known whether acute stress regulates phasic dopamine release to impact associative learning.

To address this question, male rats were exposed to a single episode of restraint stress prior to training on a pavlovian conditioning task using food rewards. We monitored dopamine release in the ventral medial striatum (VMS) and ventral lateral striatum (VLS) throughout training to determine whether stress altered the dopamine response to rewards or their predictors. Additionally, we performed local pharmacological manipulations 
to establish whether stress-induced behavioral changes required dopamine transmission.

\section{Materials and Methods}

Subjects and surgery. The University of Texas at San Antonio Institutional Animal Care and Use Committee approved all procedures. Male CD IGS Sprague Dawley rats (Charles River Laboratories; RRID: RGD_734476) were pair housed upon arrival, allowed ad libitum access to water and chow, and maintained on a $12 \mathrm{~h}$ light/dark cycle. Voltammetry electrodes were surgically implanted under isoflurane anesthesia in rats weighing 300-400 g. Carbon fiber electrodes were placed bilaterally targeting the VMS or VLS (relative to bregma: $1.3 \mathrm{~mm}$ anterior; $\pm 1.3 \mathrm{~mm}$ lateral; $7.0 \mathrm{~mm}$ ventral or $1.3 \mathrm{~mm}$ anterior; $\pm 2.7 \mathrm{~mm}$ lateral; $7.3 \mathrm{~mm}$ ventral, respectively), along with an $\mathrm{Ag} / \mathrm{AgCl}$ reference electrode placed under the skull. Bilateral stainless steel guide cannulae (InVivo One) were implanted $1 \mathrm{~mm}$ dorsal to the VLS. Following surgery, rats were single housed for the duration of the experiment and allowed to recover for 1-3 weeks before behavioral procedures. Electrode and cannula placements are depicted in Figure 1. The microinjection area is based on the spread of an equivalent volume of Evans Blue dye.

Behavioral procedures. At $\geq 7 \mathrm{~d}$ postsurgery, rats were placed on mild dietary restriction to $90 \%$ of their free feeding weight, allowing for a weekly increase of $1.5 \%$. Rats were handled regularly before behavioral testing commenced. All behavioral sessions occurred during the light cycle in operant boxes (Med Associates) with a grid floor, a house light, a recessed food tray equipped with an infrared beam-break detector, and a white noise generator. To familiarize the animals with the operant chamber and food retrieval from the tray, rats first received one to two magazine training sessions in which 20 unsignaled food pellets $(45 \mathrm{mg}$; Bio-Serv) were delivered at a $90 \mathrm{~s}$ variable interval. Rats then underwent 10 pavlovian reward conditioning sessions composed of 50 trials each. Trials consisted of a $5 \mathrm{~s}$ white noise conditioned stimulus (CS) presentation terminating with the delivery of a single food pellet unconditioned stimulus (US) and $4.5 \mathrm{~s}$ illumination of the tray light. Trials were separated by a 40,55 , or $70 \mathrm{~s}$ intertrial interval. We monitored head entries into the food tray across training sessions. Conditioned responding was quantified as the change in the rate of head entries during the $5 \mathrm{~s}$ CS relative to the $5 \mathrm{~s}$ preceding the CS delivery (Fonzi et al., 2017). Response latency was calculated as the time elapsed until the first head entry during the CS. To assay response vigor, we calculated the head entry rate during the interval from the first entry to the end of the CS. We then took the difference between this adjusted response rate relative to the head entry rate in the $5 \mathrm{~s}$ preceding the CS delivery.

Restraint stress. In a novel room, rats were confined in a clear acrylic tail vein restrainer (Braintree Scientific) for 20-30 min. Control rats were introduced to a clean, empty cage for an equivalent period of time. This control procedure was designed to mimic the sensory aspects of the stress procedure without eliciting threat responses (Beerling et al., 2011). Rats were then transferred to a clean recovery cage in the familiar testing area for $5 \mathrm{~min}$. Following recovery, rats were connected to the voltammetric amplifier in the operant chamber and electrodes were cycled for 15 min prior to pavlovian training sessions, allowing for a total interval of $20 \mathrm{~min}$ from the end of the stress/control procedure to the start of training. An additional group of animals was returned to their home cages for $100 \mathrm{~min}$ after recovery, allowing for a $2 \mathrm{~h}$ interval from the end of the stress/control procedure to the start of training.

Pharmacology. Flupenthixol dihydrochloride (Tocris Bioscience) was dissolved in sterile $0.9 \% \mathrm{NaCl}$. Rats received bilateral $0.5 \mu \mathrm{l}$ microinjections of flupenthixol (10 $\mu \mathrm{g} / \mathrm{side})$ or vehicle into the ventral lateral striatum at $0.25 \mu \mathrm{l} / \mathrm{min}$. The injectors were removed $1 \mathrm{~min}$ after the infusion ended. Behavioral sessions commenced $30 \mathrm{~min}$ after the intra-VLS microinjections (Saunders and Robinson, 2012).

Voltammetry recordings and analysis. Indwelling carbon fiber microelectrodes were connected to a head-mounted amplifier to monitor dopamine release in behaving rats using fast-scan cyclic voltammetry, as described previously (Clark et al., 2010; Fonzi et al., 2017; Oliva and Wanat, 2019; Stelly et al., 2019). During voltammetric scans, the potential applied to the carbon fiber was ramped in a triangular waveform from $-0.4 \mathrm{~V}$ (vs $\mathrm{Ag} / \mathrm{AgCl}$ ) to $+1.3 \mathrm{~V}$ and back at a rate of $400 \mathrm{~V} / \mathrm{s}$. Scans occurred at $10 \mathrm{~Hz}$ with the electrode potential held at $-0.4 \mathrm{~V}$ between scans. Dopamine was chemically verified by obtaining high correlation of the cyclic voltammogram during a reward-related event with that of a dopamine standard (correlation coefficient $r^{2} \geq 0.75$ by linear regression). Voltammetry data for a session were excluded from analysis if the detected voltammetry signal did not satisfy the chemical verification criteria, as in prior studies (Fonzi et al., 2017; Oliva and Wanat, 2019; Stelly et al., 2019). Dopamine was isolated from the voltammetry signal using chemometric analysis (Heien et al., 2005) with a standard training set accounting for dopamine, $\mathrm{pH}$, and drift. The background for voltammetry recording analysis was set at $0.5 \mathrm{~s}$ before the CS onset. CSevoked dopamine release was quantified as the mean dopamine level during the $5 \mathrm{~s}$ CS relative to the $5 \mathrm{~s}$ prior to the CS delivery (Fonzi et al., 2017). US-evoked dopamine was quantified as the peak dopamine level during the $2.5 \mathrm{~s}$ following the pellet delivery relative to the $0.5 \mathrm{~s}$ preceding the pellet delivery. While we refer to this signal as a US-evoked dopamine response, we note that sensory elements and food consumption are additional factors that could contribute to this response. Trials were excluded if chemometric analysis failed to identify dopamine on $>25 \%$ of the data points. The change in dopamine concentration was estimated based on the average postimplantation electrode sensitivity $(34 \mathrm{nA} / \mu \mathrm{M}$; Clark et al., 2010).

Experimental design and statistical analysis. Rats were assigned to stressed or control groups in an unbiased manner. We performed all statistical analyses in GraphPad Prism 8. All data are plotted as the mean \pm SEM. A mixed-effects model fit (restricted maximum-likelihood method) was used to analyze effects on behavioral measures and dopamine responses. Student's unpaired $t$ test with Welch's correction was used to compare dopamine responses in VMS subregions. The significance level was set to $\alpha=0.05$ for all tests.

Histology. Rats with were anesthetized, electrically lesioned via the voltammetry electrodes, and perfused intracardially with $4 \%$ paraformaldehyde. Brains were extracted and postfixed in the paraformaldehyde solution for a minimum of $24 \mathrm{~h}$, then were transferred to $15 \%$ and $30 \%$ sucrose in PBS. Tissue was cryosectioned and stained with cresyl violet. Implant locations were mapped to a standardized rat brain atlas (Paxinos and Watson, 2004). The VMS and VLS were delineated by the anatomical boundary formed by the lateral edge of the anterior commissure.

\section{Results}

\section{A single stress exposure enhances conditioned responding to} reward-predictive stimuli

We examined how a single episode of restraint stress affected the acquisition of conditioned behavioral responses to a reward-predictive cue. As a control, a separate group of rats was exposed to a clean, empty cage for an equivalent period of time. Rats underwent the stress or control treatment 20 min prior to the first pavlovian conditioning session. Training continued for nine additional daily sessions without any further stress experience (Fig. $2 A$ ). Each session consisted of 50 presentations of a $5 \mathrm{~s}$ audio CS that terminated with the delivery of a single food pellet US (Fig. $2 B$ ). Rats exposed to a single episode of stress exhibited a greater level of conditioned responding relative to controls (treatment effect: $F_{(1,35)}=8.22, p=$ 0.007; session effect: $F_{(1.6,55.3)}=17.62, p<0.0001$; interaction: $F_{(9,305)}=1.81, p=0.065 ; n=16$ controls, 21 stressed rats; Fig. $\left.2 C\right)$. Stress did not alter the latency to approach the food tray in response to CS onset (session effect: $F_{(1.9,66.1)}=25.65, p<0.0001$; treatment effect: $F_{(1,35)}=0.80, p=0.38$; interaction: $F_{(9,305)}=0.83$, $p=0.59$; Fig. $2 D)$. The number of tray entries during the intertrial interval was also unaffected by stress exposure, indicating no change in overall activity (treatment effect: $F_{(1,35)}=1.03, p=0.32$; session effect: $F_{(1.6,53.5)}=2.09, p=0.14$; interaction: $F_{(9,305)}=0.74$, $p=0.67$; Fig. $2 E$ ). Together, these results demonstrate that stress 


\section{Voltammetry electrode placement}

Ventral medial striatum
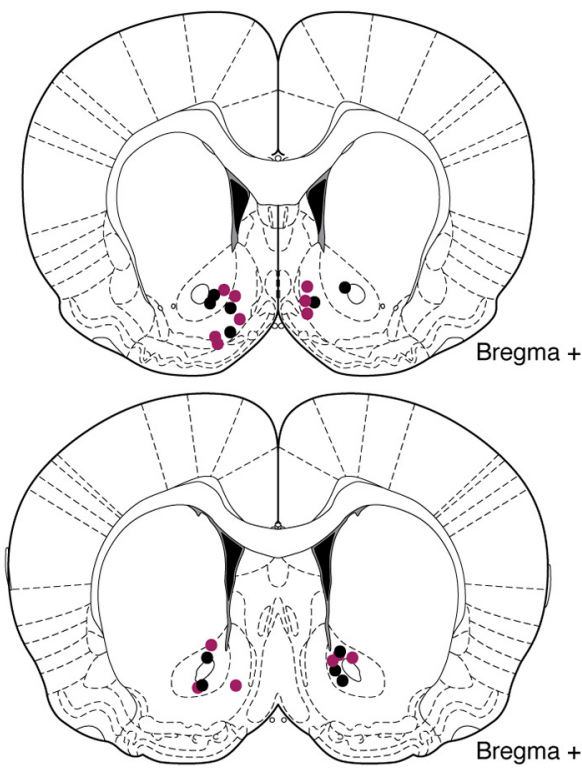

Control; Stressed

B

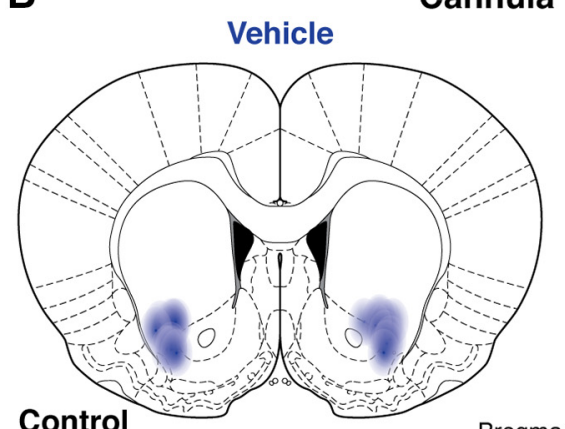

Bregma $+1.68 \mathrm{~mm}$
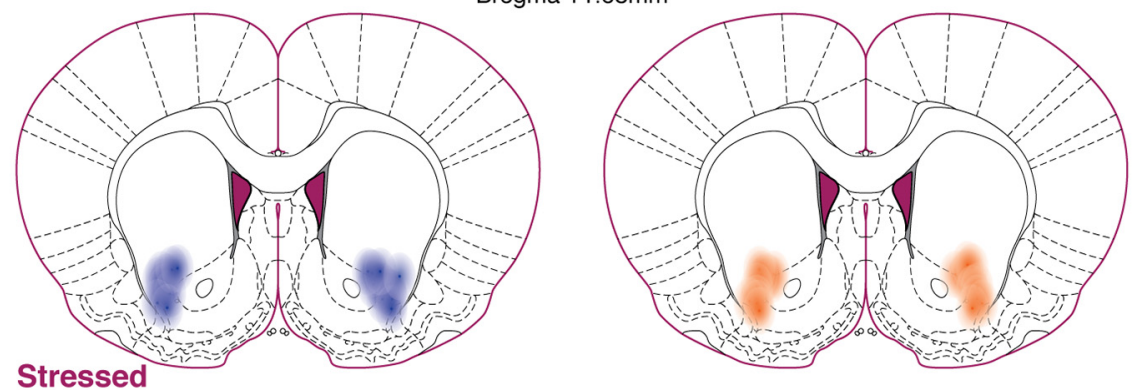

Figure 1. Voltammetry electrode and cannula placement. $\boldsymbol{A}$, Histologically verified locations of voltammetry electrodes in control rats (black circles) and stressed rats (magenta circles). The lateral edge of the anterior commissure was used as the boundary of the ventral medial (left) and ventral lateral (right) striatum. $\boldsymbol{B}$, Histologically verified locations of microinjector tips and approximate infusion area of vehicle (left, blue) and flupenthixol (right, orange) in control rats (above, black border) and stressed rats (below, magenta border).

selectively increases conditioned responses toward reward-predictive cues.

Stressful experience produces physiological effects ranging from minutes to hours (Carrasco and Van de Kar, 2003). To determine the temporal window in which acute stress impacts pavlovian reward learning, we increased the interval between the stressor and the first conditioning session to $2 \mathrm{~h}$ (Fig. $2 F$ ). Conditioned responding did not differ between stressed and control rats in this cohort (treatment effect: $F_{(1,17)}=0.13, p=0.72$; session effect: $F_{(1.8,31.3)}=$
10.74, $p=0.0004$; interaction: $F_{(9,153)}=0.42$, $p=0.92 ; n=9$ controls, 10 stressed rats; Fig. $2 G)$. While all rats demonstrated reduced response latency with training, there was no difference between treatment groups (session effect: $F_{(2.9,49.8)}=63.32, p<0.0001$; treatment effect: $F_{(1,17)}=0.28, p=0.61$; interaction: $F_{(9,153)}=1.05, p=0.41 ;$ Fig. $\left.2 H\right)$. Furthermore, stress did not alter non-CS tray entries (treatment effect: $F_{(1,17)}=1.20, p=0.29$; session effect: $F_{(1.7,28.8)}=11.54, p=0.0004$; interaction: $F_{(9,153)}=0.35, p=0.96$; Fig. $\left.2 I\right)$. These findings demonstrate that conditioned responding is not altered if the stress exposure is temporally distantfrom the training experience.

We next examined whether stress similarly facilitated conditioned responding in well trained rats. Rats were trained for five pavlovian conditioning sessions before undergoing a single episode of restraint stress prior to the sixth training session (Fig. 2J). Acute stress did not impact conditioned responding in well trained rats (treatment effect: $F_{(1,20)}=0.69, p=$ 0.42 ; session effect: $F_{(2.0,39.7)}=20.44, p<$ 0.0001; interaction: $\left.F_{(9,178)}=1.08, p=0.38\right)$. There was no effect of stress on response latency (treatment effect: $F_{(1,20)}=0.04, p=0.85$; session effect: $F_{(2.9,58.1)}=49.31, p<0.0001$; interaction: $F_{(9,178)}=1.23, p=0.28$; Fig. $\left.2 L\right)$ or non-CS tray entries (treatment effect: $F_{(1,20)}=$ $0.0021, p=0.96$; session effect: $F_{(1.4,28.5)}=4.85$, $p=0.02$; interaction: $F_{(9,178)}=0.62, p=0.78$; Fig. 2M). These results illustrate that acute stress does not influence the expression of a previouslyacquired conditioned response.

\section{Stress selectively enhances reward- evoked dopamine release in the ventral lateral striatum}

Dopamine transmission in the ventral striatum is required for the acquisition of conditioned responding (Darvas et al., 2014). Furthermore, increasing ventral striatal phasic dopamine release is sufficient to confer conditioned motivational properties to neutral stimuli (Saunders et al., 2018). The enhanced conditioned responding observed after acute stress could therefore reflect a stress-induced increase in ventral striatal dopamine. To address this possibility, we performed voltammetry recordings of dopamine release in the ventral striatum across pavlovian conditioning sessions. We analyzed dopamine release during the first five sessions, as conditioned responding was insensitive to the stress manipulation after this point (Fig. 2J-M).

We first examined dopamine signaling in the VMS given the involvement of the VMS in reward-related behaviors (Kelley, 2004; Tsutsui-Kimura et al., 2017a). Consistent with prior studies (Stuber et al., 2008; Flagel et al., 2011), dopamine release in the VMS was time-locked to both the CS and the US (Fig. 3B,C). The CS dopamine response did not differ between stressed and control 
A Experimental timeline
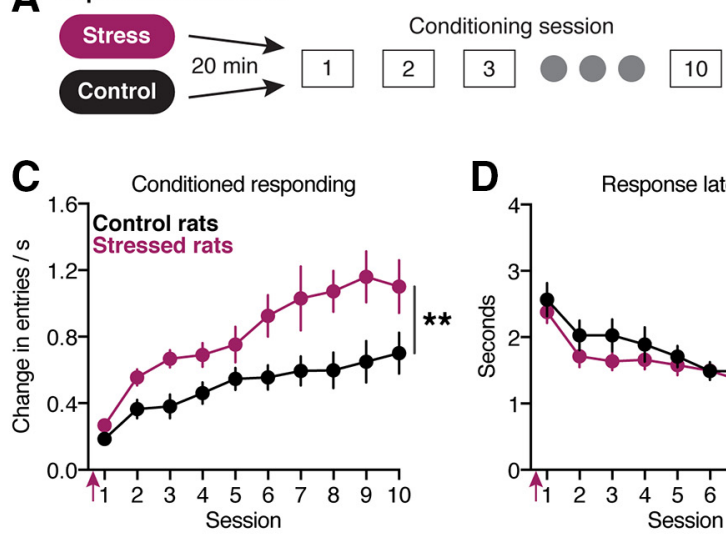

B Pavlovian reward task (50 trials per session)

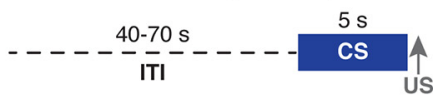

E

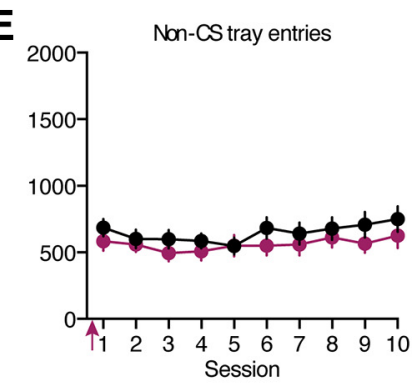

\section{F Stress}

Control

G

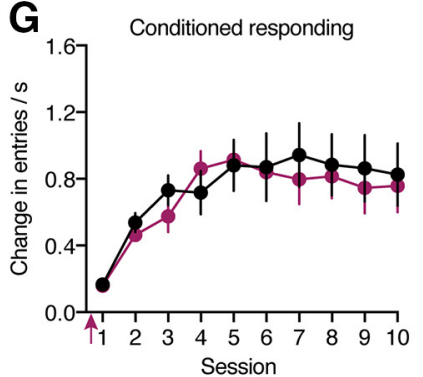

$\mathbf{J}$
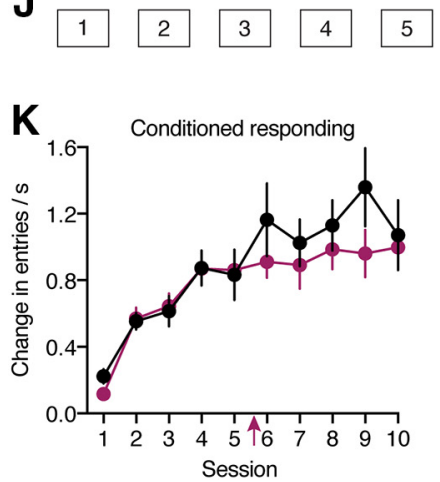
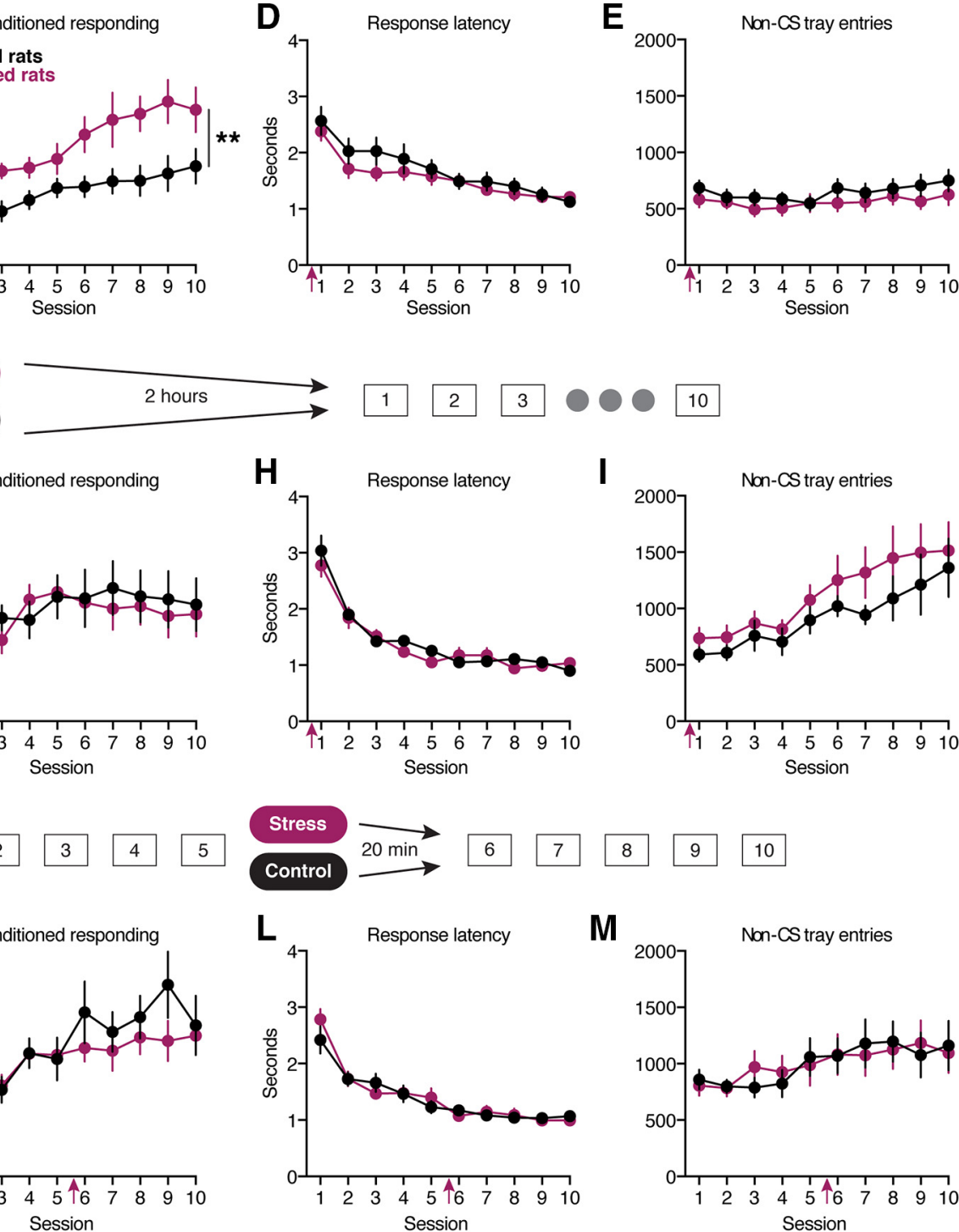

Figure 2. A single stress experience enhances subsequent pavlovian conditioning. $\boldsymbol{A}$, Training paradigm. Animals are stressed once, 20 min prior to the first conditioning session. $\boldsymbol{B}$, Task structure. $\boldsymbol{C}$, Elevated conditioned responding to the reward-predictive CS in rats stressed before the first training session. Magenta arrows denote restraint stress/control procedure. $\boldsymbol{D}$, Latency to head entry. $\boldsymbol{E}$, Non-CS tray entries. $\boldsymbol{F}$, Training paradigm with a $2 \mathrm{~h}$ delay between the stress/control treatment and the start of conditioning. $\boldsymbol{G}$, Conditioned responding is not increased when training begins $2 \mathrm{~h}$ after the stressor. $\boldsymbol{H}$, Latency to head entry. $\boldsymbol{I}$, Non-CS tray entries. $\boldsymbol{J}$, Training paradigm with stress/control treatment occurring 20 min prior to the sixth conditioning session. $\boldsymbol{K}$, Conditioned responding is not increased when stress experience occurs after acquisition of the task. $\boldsymbol{L}$, Latency to head entry. $\boldsymbol{M}$, Non-CS tray entries. ${ }^{* *} p<0.01$.

rats (treatment effect: $F_{(1,20)}=0.64, p=0.43$; session effect: $F_{(2.6,47.0)}=1.14, p=0.34$; interaction: $F_{(4,71)}=0.46, p=0.76 ; n=9$ controls, 13 stressed rats; Fig. $3 D$ ). Dopamine release to the US decayed with training but was unaffected by stress exposure (treatment effect: $F_{(1,20)}=2.22, p=0.15$; session effect: $F_{(2.5,43.9)}=8.02$, $p=0.0005$; interaction: $F_{(4,71)}=1.09, p=0.37$; Fig $\left.3 E\right)$. Collectively, these results indicate that acute stress prior to the first conditioning session did not influence the VMS dopamine response to rewards or reward-predictive cues.

Our voltammetry recordings of VMS dopamine included electrodes located in the medial aspects of the nucleus accumbens core and nucleus accumbens shell. Depending on the task, distinct patterns of dopamine signaling can emerge between the medial nucleus accumbens core and shell (Badrinarayan et al.,
2012; Oleson et al., 2012; Saddoris et al., 2015; Ko and Wanat, 2016). We therefore examined the dopamine responses during the first training session to determine whether dopamine release differed between these VMS subregions. However, there was no difference between medial accumbens core and shell regions when examining the dopamine response in control rats (unpaired $t$ test; CS: $t_{(2.6)}=0.13, p=0.91$; US: $t_{(5.7)}=0.15, p=$ $0.89 ; n=5$ cores, 3 shells) or stressed rats (CS: $t_{(5.2)}=0.90, p=$ 0.41 ; US: $t_{(8.9)}=1.09, p=0.30 ; n=5$ cores, 6 shells). Recent studies have also illustrated heterogeneity of VMS dopamine responses to rewarding stimuli along the dorsal-ventral axis (de Jong et al., 2019; Yuan et al., 2019). We therefore compared the dopamine signals during the first training session from electrodes that were either dorsal or ventral to the anterior commissure. 

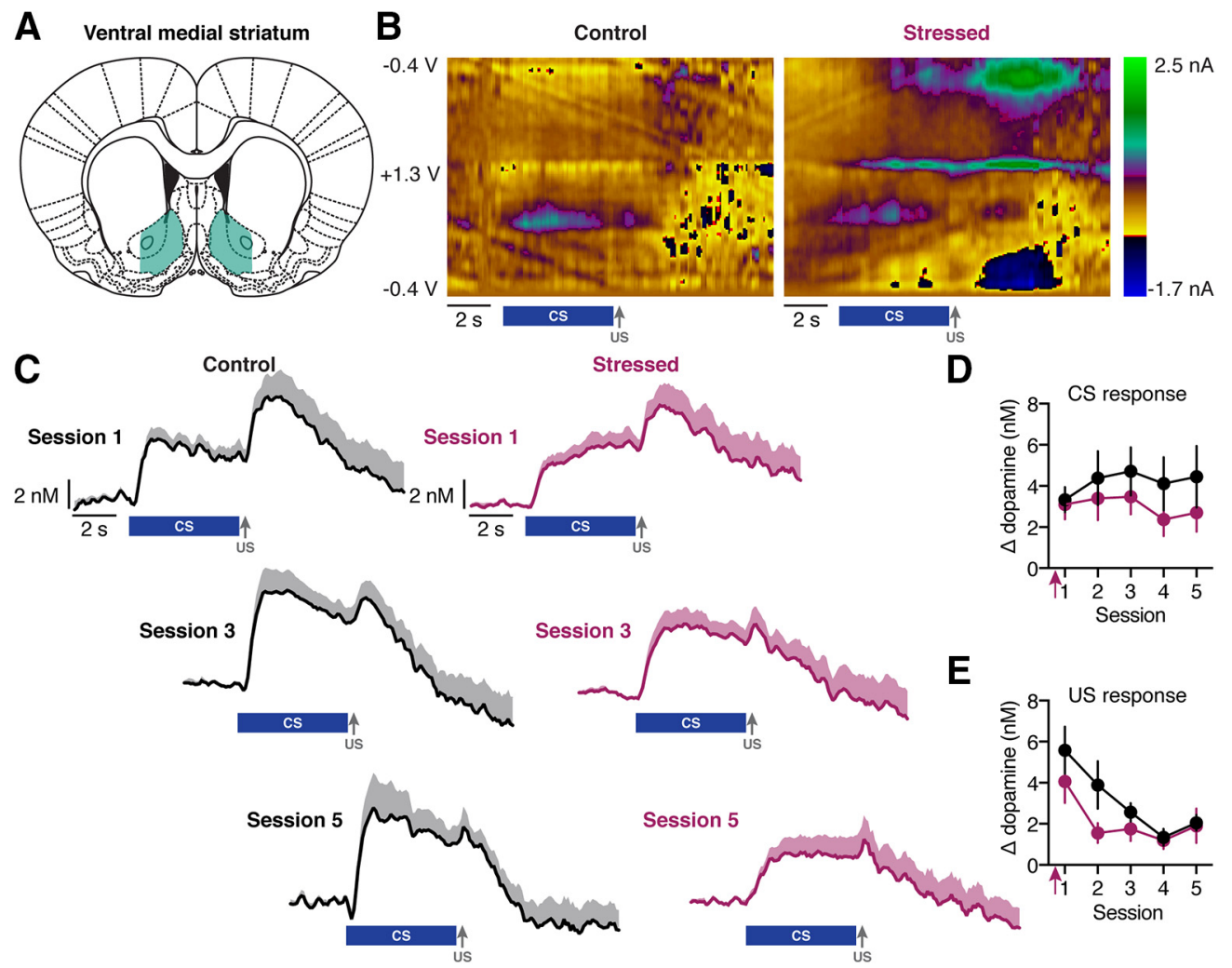

Stressed

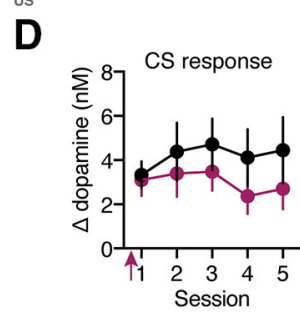

Figure 3. Acute stress does not alter dopamine signals in the VMS. $\boldsymbol{A}$, Voltammetry recordings were taken from the VMS (shaded in cyan). $\boldsymbol{B}$, Representative color plots of voltammetry recordings during session 3 from a single electrode in a control rat (left) and a stressed rat (right). C, Average dopamine signals across electrodes in control rats (left) and stressed rats (right) during the first, third, and fifth training sessions. The blue bar denotes CS presentation and the gray arrow denotes reward delivery. D, Average CS-evoked dopamine release. Magenta arrows denote restraint stress/control procedure. $\boldsymbol{E}$, Average US-evoked dopamine release.

There was no difference in CS-evoked or US-evoked dopamine release between dorsal and ventral electrodes in control rats (unpaired $t$ test; CS: $t_{(5.9)}=1.65, p=0.15$; US: $t_{(5.0)}=0.28, p=$ $0.79 ; n=5$ dorsal, 5 ventral) or stressed rats (CS: $t_{(4.2)}=1.15, p=$ 0.31 ; US: $t_{(8.5)}=0.0072, p=0.99 ; n=6$ dorsal, 5 ventral). These results indicate cue-evoked and reward-evoked dopamine signals throughout the VMS are largely uniform in this pavlovian conditioning task.

Increasing evidence highlights that the VLS contributes to reward-related behaviors (Natsubori et al., 2017; Tsutsui-Kimura et al., 2017a,b). Furthermore, aversive experience increases excitatory transmission to dopamine neurons projecting to the VLS (Lammel et al., 2011). As such, acute stress could enhance dopamine signaling in the VLS. Similar to the VMS, we identified time-locked dopamine signals in the VLS in response to the CS and US across pavlovian conditioning sessions (Fig. 4B,C). CSevoked dopamine release increased with training but did not differ between stressed and control rats (treatment effect: $F_{(1,21)}=$ $0.92, p=0.35$; session effect: $F_{(3.2,57.1)}=5.72, p=0.0014$; interaction: $F_{(4,72)}=1.0, p=0.41 ; n=11$ controls, 12 stressed rats; Fig. $4 D)$. However, the US-evoked dopamine release was elevated across sessions in stressed rats (treatment effect: $F_{(1,21)}=8.16$, $p=0.0095$; session effect: $F_{(2.6,46.2)}=5.30, p=0.0048$; interaction: $F_{(4,72)}=0.66, p=0.62$; Fig. $\left.4 E\right)$. Stress therefore selectively upshifts reward-evoked dopamine signals in the VLS.

The stress-induced increase in VLS dopamine release precedes the increase in conditioned responding We next analyzed the data in 10-trial bins to identify when the effect of stress on behavior and dopamine release first emerged.
There was no difference in conditioned responding between stressed and control groups during session 1 (treatment effect: $F_{(1,35)}=2.75, p=0.11$; trial effect: $F_{(2.9,102)}=15.75, p<0.0001$; interaction: $F_{(4,140)}=2.04, p=0.09 ; n=16$ controls, 21 stressed rats; Fig. $5 A$ ). However, stressed rats exhibited an elevated level of conditioned responding throughout session 2 (treatment effect: $F_{(1,35)}=6.95, p=0.01$; trial effect: $F_{(3.1,107.8)}=0.75, p=$ 0.53 ; interaction: $\left.F_{(4,140)}=0.53, p=0.72\right)$. In contrast, the USevoked dopamine response in the VLS was increased in stressed rats throughout session 1 (treatment effect: $F_{(1,18)}=4.55, p=$ 0.047 ; trial effect: $F_{(3.1,55.4)}=7.6, p=0.0002$; interaction: $F_{(4,72)}=$ $2.25, p=0.072 ; n=9$ controls, 11 stressed rats; Fig. $5 B)$ and session 2 (treatment effect: $F_{(1,18)}=8.64, p=0.0088$; trial effect: $F_{(2.5,45.5)}=2.1, p=0.12$; interaction: $\left.F_{(4,72)}=1.22, p=0.31\right)$. We performed correlational analyses and found no relationship between the US-evoked dopamine response during session 1 and conditioned responding during session $1\left(r^{2}=0.00056, p=0.93\right)$ or session $2\left(r^{2}=0.064, p=0.33\right)$. Collectively, these results illustrate the stress-induced increase in VLS dopamine release precedes the increase in conditioned responding.

Stress recruits VLS dopamine signaling to regulate appetitive learning

We next examined whether VLS dopamine signaling was required for the stress-induced enhancement of conditioned responding. To address this, rats were implanted with bilateral cannulae targeting the VLS for local pharmacological manipulations. The $\mathrm{D}_{1} / \mathrm{D}_{2}$ dopamine receptor antagonist flupenthixol (10 $\mu \mathrm{g} / \mathrm{side}$ ) or vehicle was infused into the VLS $30 \mathrm{~min}$ before the first five sessions. Rats were trained without injections for five 

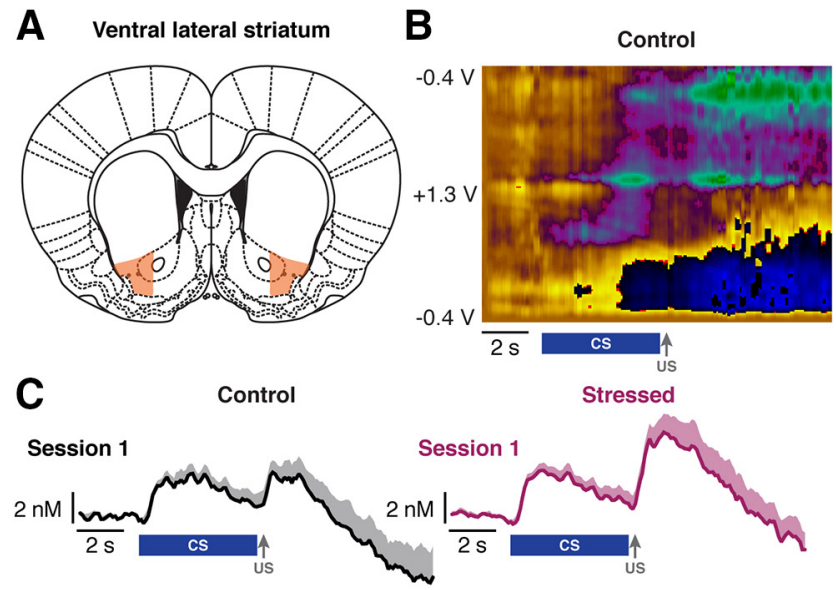

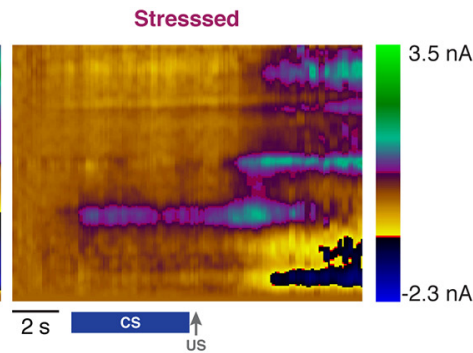

D
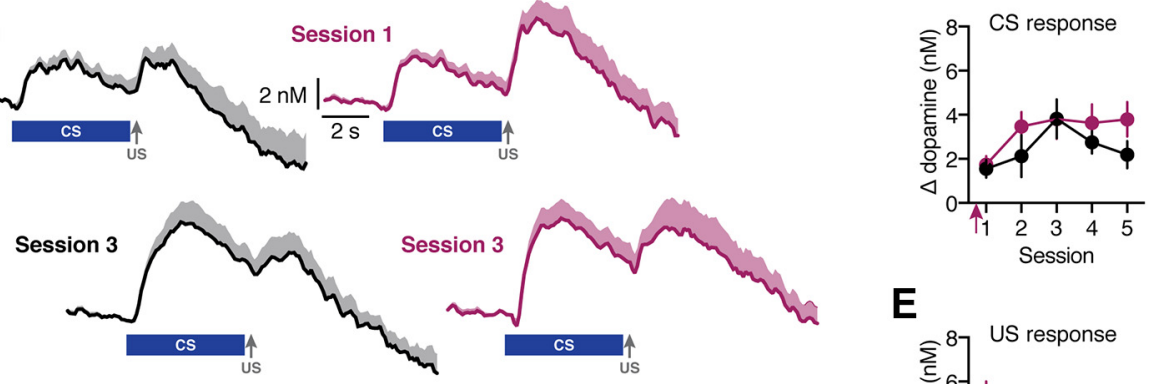

E

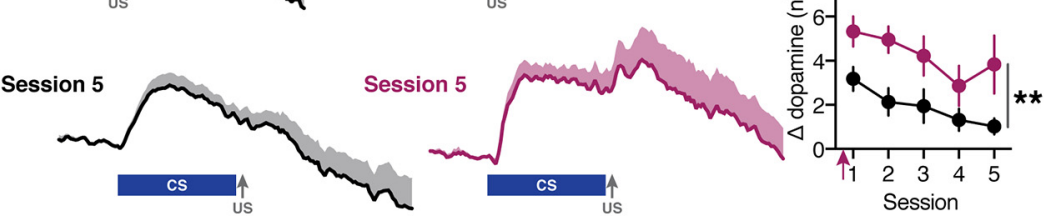

Figure 4. Acute stress selectively enhances US-evoked dopamine signals in the VLS. $\boldsymbol{A}$, Voltammetry recordings were taken from the VLS (shaded in orange). $\boldsymbol{B}$, Representative color plots of voltammetry recording during session 3 from a single electrode in a control rat (left) and a stressed rat (right). $C$, Average dopamine responses across electrodes in control rats (left) and stressed rats (right) during the first, third, and fifth training sessions. The blue bar denotes CS presentation, and the gray arrow denotes reward delivery. $\boldsymbol{D}$, Average CS-evoked dopamine release does not differ between groups. Magenta arrows denote restraint stress/control procedure. $\boldsymbol{E}$, Average US-evoked dopamine release is enhanced in stressed rats. ${ }^{* *} p<0.01$.
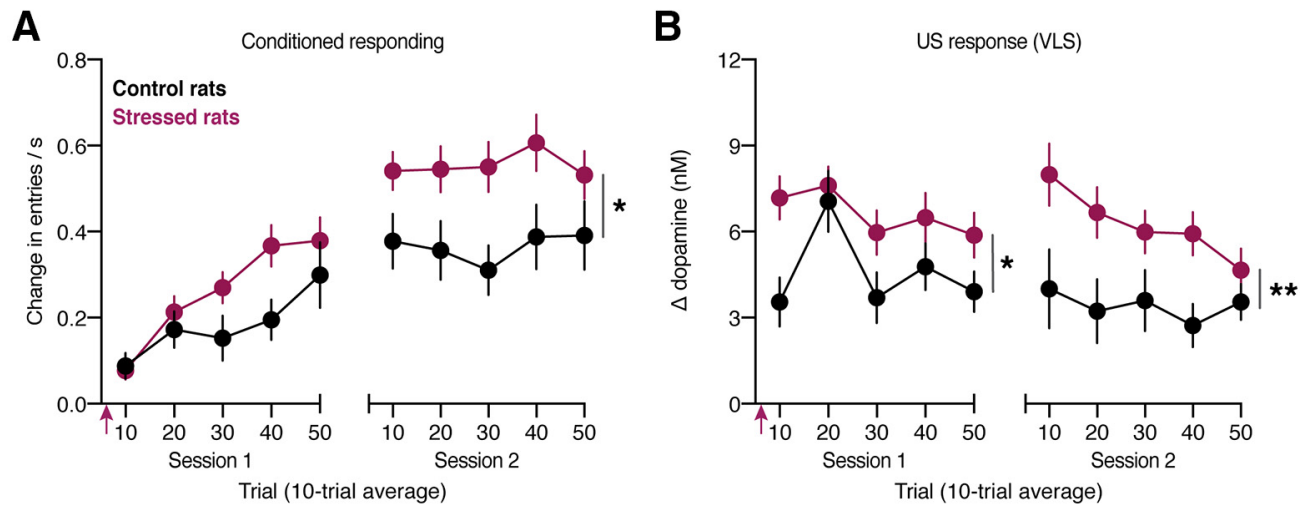

Figure 5. Stress-induced elevation of US-evoked VLS dopamine responses precedes the enhancement of conditioned responding. $A$, Conditioned responding during the first two training sessions, plotted in 10-trial bins. Conditioned responding was not significantly elevated in stressed rats during session 1. A group difference emerged during session 2. B, US-evoked VLS dopamine signals during sessions 1 and 2, plotted in 10-trial bins. The US-evoked dopamine response in stressed rats was elevated in sessions 1 and $2 .{ }^{*} p<0.05$, ${ }^{* *} p<0.01$.

additional sessions to differentiate acute versus sustained behavioral effects of the flupenthixol treatment (Fig. 6A).

In control rats, VLS injections of flupenthixol had no effect on conditioned responding during sessions $1-5$ (drug effect: $F_{(1,20)}=1.45, p=0.24 ;$ session effect: $F_{(2.2,44.0)}=23.20, p<$ 0.0001 ; interaction: $F_{(4,80)}=1.36, p=0.26, n=11$ vehicle, 11 flupenthixol; Fig. 6B). However, flupenthixol-treated rats exhibited lower levels of conditioned responding relative to vehicle-treated rats in subsequent sessions in which no injection was administered (prior treatment effect: $F_{(1,20)}=6.03, p=0.023$; session effect: $F_{(2.9,58.5)}=0.91, p=0.44$; interaction: $F_{(4,80)}=0.39, p=$ 0.82 ). In contrast, flupenthixol did not affect response latency acutely (drug effect: $F_{(1,20)}=1.37, p=0.26$; session effect:
$F_{(2.3,46.5)}=9.24, p=0.0002$; interaction: $F_{(4,80)}=0.59, p=0.67$; Fig. $6 C$ ) or during subsequent sessions without injections (prior treatment effect: $F_{(1,20)}=0.00062, p=0.98$; session effect: $F_{(3.5,70.2)}=4.59, p=0.0035$; interaction: $\left.F_{(4,80)}=0.98, p=0.42\right)$. Together, these data from control rats illustrate that manipulating VLS dopamine signaling during early training sessions influences conditioned responding in later training sessions.

In stressed rats, VLS injections of flupenthixol acutely suppressed conditioned responding during session 1-5 (drug effect: $F_{(1,21)}=19.93, p=0.0002$; session effect: $F_{(2.2,45.9)}=22.82, p<$ 0.0001 ; interaction: $F_{(4,84)}=3.85, p=0.0064, n=12$ vehicle, 11 flupenthixol; Fig. $6 D$ ). Conditioned responding was also reduced in flupenthixol-treated rats throughout subsequent sessions in 
A
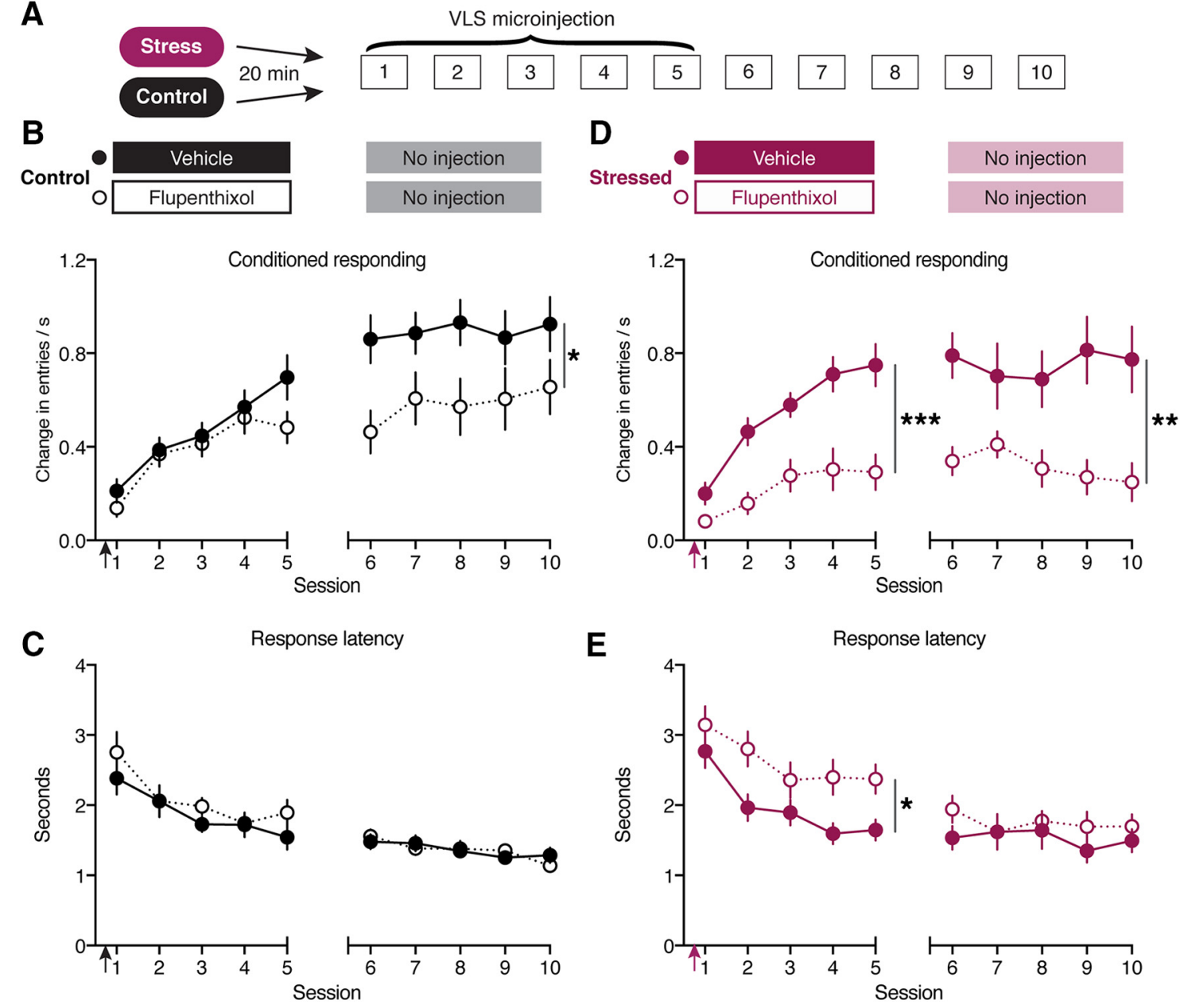

Figure 6. VLS dopamine signals are required for conditioning in stressed rats. $\boldsymbol{A}$, Training paradigm. Rats were stressed once, 20 min prior to the first session. Flupenthixol or vehicle was infused to the VLS before each of the first five training sessions. Training continued for five additional sessions without injections. $\boldsymbol{B}$, Conditioned responding acquisition was not initially impaired by flupenthixol treatment in control rats, but a delayed deficit emerged with additional training. $\boldsymbol{C}$, Response latency was not altered by flupenthixol treatment in controls. $\mathbf{D}$, Flupenthixol treatment impaired conditioned responding in stressed rats. E, Flupenthixol treatment reversibly increased the latency in stressed rats. ${ }^{*} p<0.05$, ${ }^{* *} p<0.01,{ }^{* * *} p<0.001$.

which no injection was administered (prior treatment effect: $F_{(1,21)}=10.64, p=0.0037$; session effect: $F_{(2.4,51.1)}=0.57, p=0.60$; interaction: $F_{(4,84)}=1.85, p=0.13$; Fig. $\left.6 D\right)$. Furthermore, flupenthixol acutely slowed the latency to respond in stressed rats (drug effect: $F_{(1,21)}=6.41, p=0.019$, session effect: $F_{(1.9,40.1)}=18.39, p<$ 0.0001 ; interaction: $F_{(4,84)}=1.23, p=0.31$ ), but this effect was not observed in subsequent sessions (prior treatment effect: $F_{(1,21)}=$ $0.92, p=0.35$; session effect: $F_{(3.5,73.9)}=1.08, p=0.37$; interaction: $F_{(4,84)}=0.95, p=0.44$; Fig. $\left.6 E\right)$. These results illustrate that antagonizing dopamine receptors in the VLS of stressed rats acutely impaired response latency and conditioned responding. However, only the deficits in conditioned responding (and not response latency) were sustained when VLS dopamine receptors were no longer blocked.

The effect of flupenthixol treatment on conditioned responding could be partially driven by an increased latency to approach the food tray, which reduces the time available for conditioned head entries. To eliminate the confound of response latency, we recalculated the CS-evoked response rate based on the interval between the first head entry and the US delivery ("response vigor"; Fig. 7A). In control rats, response vigor was not impaired during flupenthixol treatment sessions (drug effect: $F_{(1,20)}=1.54$, $p=0.23$; session effect: $F_{(2.7,54.9)}=18.92, p<0.0001$; interaction: $F_{(4,80)}=0.91, p=0.46$; Fig. $\left.7 B\right)$. However, response vigor was reduced in flupenthixol-treated rats during subsequent sessions without injections (prior treatment effect: $F_{(1,20)}=7.28, p=$ 0.014 ; session effect: $F_{(2.6,51.5)}=0.50, p=0.65$; interaction: $\left.F_{(4,80)}=0.42, p=0.79\right)$.

We next examined the response vigor in control rats during session 5 (last treatment session) and session 6 (no treatment) to identify when responding became sensitive to VLS dopamine signaling. Comparing the behavior between sessions 5 and 6 identified a significant interaction between flupenthixol treatment and training session (treatment effect: $F_{(1,20)}=5.97, p=$ 0.024 ; session effect: $F_{(1,20)}=1.33, p=0.26$; interaction: $F_{(1,20)}=$ 13.02, $p=0.0018$; Sidak's multiple-comparison test: session 5, $p=0.34$; session $6, p=0.0035$ ). We further analyzed sessions 5 and 6 in 10-trial bins to examine within-session effects of flupenthixol. Response vigor differed across trials between vehicletreated and flupenthixol-treated rats within session 6 , but not session 5 (session 5: drug effect: $F_{(1,20)}=2.99, p=0.099$; trial effect: $F_{(2.7,53.2)}=0.29, p=0.81$; interaction: $F_{(4,80)}=0.75, p=$ 0.56; session 6: prior treatment effect: $F_{(1,20)}=9.47, p=0.0059$; trial effect: $F_{(3.3,66.5)}=1.16, p=0.33$; interaction: $F_{(4,80)}=0.62$, $p=0.65$; Fig. $7 C$ ). These results suggest that in control rats, session 5 marks the start of critical period in which disrupting VLS dopamine transmission induces lasting impairments expressed in the following sessions. 


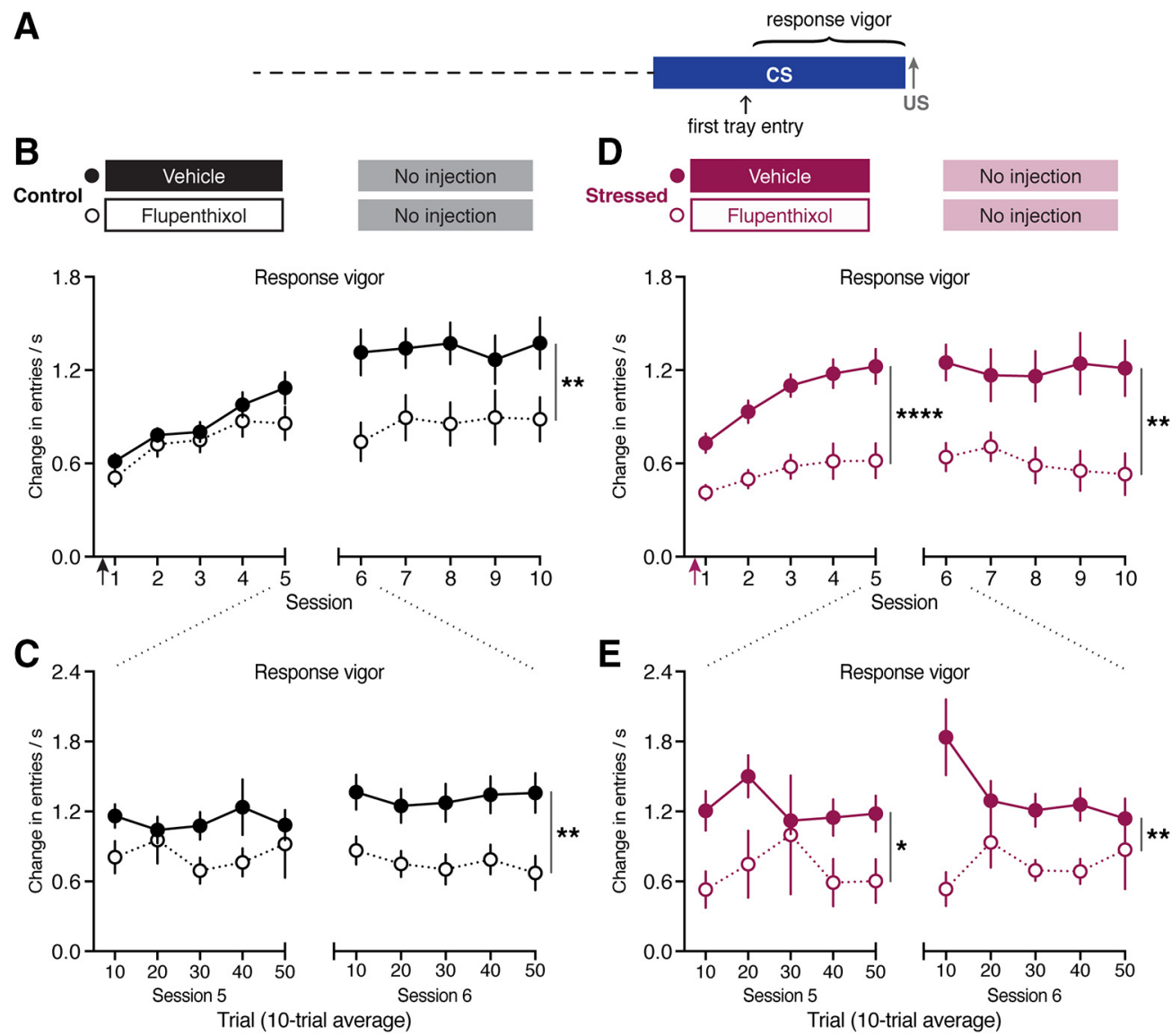

Figure 7. Stress shifts the timing of behavioral regulation by VLS dopamine transmission. $\boldsymbol{A}$, Calculation of response vigor. $\boldsymbol{B}$, Response vigor was not initially impaired by flupenthixol treatment in control rats, but a delayed deficit emerged in subsequent sessions without drug treatment. C, Response vigor in control rats during session 5 (VLS microinjection of vehicle or flupenthixol) and session 6 (no injection), plotted in 10-trial bins. D, Flupenthixol treatment impairs response vigor in stressed rats. $\boldsymbol{E}$, Response vigor was impaired in sessions 5 and 6 in stressed rats. ${ }^{*} p<0.05,{ }^{* *} p<0.01,{ }^{* * * *} p<0.0001$.

In stressed rats, flupenthixol acutely reduced response vigor (drug effect: $F_{(1,21)}=33.80, p<0.0001$; session effect: $F_{(2.2,46.0)}=$ 9.0, $p=0.0003$; interaction: $F_{(4,84)}=1.42, p=0.24 ;$ Fig $\left.7 D\right)$, and this effect persisted throughout subsequent sessions (prior treatment effect: $F_{(1,21)}=10.37, p=0.0041$; session effect: $F_{(2.5,53.5)}=$ $0.54, p=0.63$; interaction: $\left.F_{(4,84)}=0.98, p=0.42\right)$. These results were recapitulated when examining the response vigor in 10-trial bins during session 5 (drug effect: $F_{(1,21)}=6.06, p=0.023$; trial effect: $F_{(2.4,50.5)}=0.77, p=0.49$; interaction: $F_{(4,84)}=0.80, p=$ 0.53 ) and during session 6 (prior treatment effect: $F_{(1,21)}=11.16$, $p=0.0031$; trial effect: $F_{(2.7,56.7)}=0.66, p=0.57$; interaction: $F_{(4,84)}=2.76, p=0.033$; Fig. $\left.7 E\right)$. These data indicate that flupenthixol treatment differentially influences response vigor in control and stressed rats. In support, there was a significant interaction of stress exposure and flupenthixol treatment when we examined response vigor from all groups during the first five sessions (three-way mixed-effects analysis; stress $\times$ drug interaction: $\left.F_{(1,41)}=9.60, p=0.0035\right)$. Collectively, these results illustrate that VLS dopamine transmission regulates appetitive behavior earlier in training in rats exposed to stress.

\section{Discussion}

In adverse circumstances, it is adaptive to effectively learn which stimuli predict beneficial outcomes. Prior rodent studies have shown that stress enhances the learned preference for a cocaineassociated context (Montagud-Romero et al., 2015; Tovar-Diaz et al., 2018), though it was unclear whether acute stress similarly facilitates learning driven by natural rewards. Here, we addressed this question by using a pavlovian task in which an auditory CS signaled the upcoming delivery of a food reward. We demonstrate that a single, brief episode of restraint stress induces a delayed, persistent increase in the magnitude of conditioned responding.

The effect of stress on subsequent behavior depends on the time elapsed from the stressor, as well as the duration, intensity, and frequency of the stressful experience (Schwabe et al., 2010; Joels et al., 2011; Sapolsky, 2015). Our results indicate that the influence of acute restraint stress on reward learning is time dependent, as stress administered $2 \mathrm{~h}$ prior to the first conditioning session failed to affect behavior. Additionally, we found that acute stress did not increase conditioned responding in rats that had already learned the task. Stressful experience therefore has maximal influence over behavior when it occurs early in training. We propose that a short-lived factor produced by stress exposure interacts with a dopamine-dependent synaptic plasticity mechanism engaged during the first training session to produce the enhancement of conditioned responding in subsequent sessions. Neuroendocrine signaling factors (e.g., corticotropin-releasing factor, norepinephrine, and corticosterone) that influence the induction of synaptic plasticity are secreted over distinct time intervals relative to the onset of the stressful experience. Stress induces temporally-restricted regulation of synaptic plasticity mechanisms in the hypothalamus and VTA (Bains et al., 2015; 
Tovar-Diaz et al., 2018). Collectively, our findings indicate the neuroendocrine effects of stress interact with learning processes within a distinct temporal window to produce a long-term change in behavior.

Studies examining the role of ventral striatal dopamine in appetitive behavior have primarily focused on the VMS (Cheng et al., 2003; Day et al., 2007; Stuber et al., 2008; Nicola, 2010; Flagel et al., 2011; Clark et al., 2013; Fonzi et al., 2017). However, recent findings indicate that dopaminoceptive VLS spiny projection neurons regulate aspects of reward seeking (Natsubori et al., 2017; Tsutsui-Kimura et al., 2017a,b). Our results suggest that there is a critical period mid-training in which dopamine signaling in the VLS contributes to conditioned appetitive behavior. Control rats were not impaired during the initial sessions of pharmacological blockade of VLS dopamine transmission; however, deficits were apparent in subsequent untreated sessions. In contrast, stressed rats displayed behavioral impairments during and beyond drug treatment. Acute stress may therefore shift the time when the VLS dopamine signal "comes online" to regulate behavior to an earlier point in training.

Stress selectively enhanced reward-evoked dopamine release in the VLS without affecting dopamine release in the VMS. This result is in line with previous findings demonstrating that the dopamine neurons targeting the VLS are anatomically and functionally distinct from those targeting the VMS (Ikemoto, 2007; Lammel et al., 2011; Beier et al., 2015, 2019; de Jong et al., 2019). Furthermore, VMS and VLS spiny projection neurons innervate different downstream targets (e.g., medial vs lateral ventral pallidum and VTA; Groenewegen et al., 1999; Yang et al., 2018). Reward-evoked dopamine signals encode subjective value based upon one's internal state (e.g., satiety; Lak et al., 2014; Cone et al., 2016; Papageorgiou et al., 2016; Keiflin et al., 2019). We suggest that the stress-induced increase in VLS dopamine release reflects an upshift in reward value. Physiological states produced by stress experience may thereby influence the computation of value in distinct mesolimbic circuits.

Our data illustrate that increased reward-evoked dopamine release in the VLS accompanies invigorated CS-evoked behavior. These results are in agreement with work demonstrating that reward-evoked dopamine neuronal activity, and not CS-evoked activity, is necessary to support conditioned responding (Lee et al., 2020). Furthermore, our data demonstrate that the stress-mediated change in the VLS dopamine response to reward precedes the enhancement of conditioned responding. These results are consistent with prior findings demonstrating that altered dopaminergic encoding of subjective reward value precedes a shift in choice behavior (Papageorgiou et al., 2016). The stress-mediated enhancement of dopaminergic signaling that we observed may additionally promote consolidation of associative learning from the first session, as this process is dopamine dependent (Dalley et al., 2005). We propose that the US-evoked dopamine signal mediates plasticity downstream of the VLS, and the potentiation of this signal in the first session induces a persistent increase in conditioned responding.

A single traumatic experience can exert long-lasting effects on behavior, as is the case in post-traumatic stress disorder. As such, the role of stress in behavior motivated by aversive stimuli has been studied extensively. However, traumatic stress also alters responsivity to rewards (Elman et al., 2009; Nawijn et al., 2015). Here, we demonstrate that a single stress exposure acts upon a specific mesolimbic circuit to produce lasting changes in appetitive behavior. These findings highlight the ventral lateral striatum as a critical locus for stress to modulate the neural representation of reward.

\section{References}

Abercrombie ED, Keefe KA, DiFrischia DS, Zigmond MJ (1989) Differential effect of stress on in vivo dopamine release in striatum, nucleus accumbens, and medial frontal cortex. J Neurochem 52:1655-1658.

Anstrom KK, Miczek KA, Budygin EA (2009) Increased phasic dopamine signaling in the mesolimbic pathway during social defeat in rats. Neuroscience 161:3-12.

Badrinarayan A, Wescott SA, Vander Weele CM, Saunders BT, Couturier BE, Maren S, Aragona BJ (2012) Aversive stimuli differentially modulate real-time dopamine transmission dynamics within the nucleus accumbens core and shell. J Neurosci 32:15779-15790.

Bains JS, Wamsteeker Cusulin JI, Inoue W (2015) Stress-related synaptic plasticity in the hypothalamus. Nat Rev Neurosci 16:377-388.

Beerling W, Koolhaas JM, Ahnaou A, Bouwknecht JA, de Boer SF, Meerlo P, Drinkenburg WH (2011) Physiological and hormonal responses to novelty exposure in rats are mainly related to ongoing behavioral activity. Physiol Behav 103:412-420.

Beier KT, Steinberg EE, DeLoach KE, Xie S, Miyamichi K, Schwarz L, Gao XJ, Kremer EJ, Malenka RC, Luo L (2015) Circuit architecture of VTA dopamine neurons revealed by systematic input-output mapping. Cell 162:622-634.

Beier KT, Gao XJ, Xie S, DeLoach KE, Malenka RC, Luo L (2019) Topological organization of ventral tegmental area connectivity revealed by viralgenetic dissection of input-output relations. Cell Rep 26:159-167.e6.

Carrasco GA, Van de Kar LD (2003) Neuroendocrine pharmacology of stress. Eur J Pharmacol 463:235-272.

Chang CY, Esber GR, Marrero-Garcia Y, Yau HJ, Bonci A, Schoenbaum G (2016) Brief optogenetic inhibition of dopamine neurons mimics endogenous negative reward prediction errors. Nat Neurosci 19:111-116.

Cheng JJ, De Bruin JPC, Feenstra MGP (2003) Dopamine efflux in nucleus accumbens shell and core in response to appetitive classical conditioning. Eur J Neurosci 18:1306-1314.

Clark JJ, Sandberg SG, Wanat MJ, Gan JO, Horne EA, Hart AS, Akers CA, Parker JG, Willuhn I, Martinez V, Evans SB, Stella N, Phillips PE (2010) Chronic microsensors for longitudinal, subsecond dopamine detection in behaving animals. Nat Methods 7:126-129.

Clark JJ, Collins AL, Sanford CA, Phillips PE (2013) Dopamine encoding of Pavlovian incentive stimuli diminishes with extended training. J Neurosci 33:3526-3532.

Clemens B, Wagels L, Bauchmuller M, Bergs R, Habel U, Kohn N (2017) Alerted default mode: functional connectivity changes in the aftermath of social stress. Sci Rep 7:40180.

Cone JJ, Fortin SM, McHenry JA, Stuber GD, McCutcheon JE, Roitman MF (2016) Physiological state gates acquisition and expression of mesolimbic reward prediction signals. Proc Natl Acad Sci U S A 113:1943-1948.

Dalley JW, Laane K, Theobald DE, Armstrong HC, Corlett PR, Chudasama Y, Robbins TW (2005) Time-limited modulation of appetitive Pavlovian memory by D1 and NMDA receptors in the nucleus accumbens. Proc Natl Acad Sci U S A 102:6189-6194.

Darvas M, Wunsch AM, Gibbs JT, Palmiter RD (2014) Dopamine dependency for acquisition and performance of Pavlovian conditioned response. Proc Natl Acad Sci U S A 111:2764-2769.

Day JJ, Roitman MF, Wightman RM, Carelli RM (2007) Associative learning mediates dynamic shifts in dopamine signaling in the nucleus accumbens. Nat Neurosci 10:1020-1028.

de Jong JW, Afjei SA, Pollak Dorocic I, Peck JR, Liu C, Kim CK, Tian L, Deisseroth K, Lammel S (2019) A neural circuit mechanism for encoding aversive stimuli in the mesolimbic dopamine system. Neuron 101:133-151.e7.

Elman I, Lowen S, Frederick BB, Chi W, Becerra L, Pitman RK (2009) Functional neuroimaging of reward circuitry responsivity to monetary gains and losses in posttraumatic stress disorder. Biol Psychiatry 66:1083-1090.

Flagel SB, Clark JJ, Robinson TE, Mayo L, Czuj A, Willuhn I, Akers CA, Clinton SM, Phillips PE, Akil H (2011) A selective role for dopamine in stimulus-reward learning. Nature 469:53-57.

Fonzi KM, Lefner MJ, Phillips PEM, Wanat MJ (2017) Dopamine encodes retrospective temporal information in a context-independent manner. Cell Rep 20:1765-1774.

Goodman AM, Harnett NG, Wheelock MD, Hurst DR, Orem TR, Gossett EW, Dunaway CA, Mrug S, Knight DC (2018) Anticipatory prefrontal cortex activity underlies stress-induced changes in Pavlovian fear conditioning. Neuroimage 174:237-247. 
Groenewegen HJ, Wright CI, Beijer AV, Voorn P (1999) Convergence and segregation of ventral striatal inputs and outputs. Ann N Y Acad Sci 877:49-63.

Heien ML, Khan AS, Ariansen JL, Cheer JF, Phillips PE, Wassum KM, Wightman RM (2005) Real-time measurement of dopamine fluctuations after cocaine in the brain of behaving rats. Proc Natl Acad Sci U S A 102:10023-10028.

Hermans EJ, van Marle HJ, Ossewaarde L, Henckens MJ, Qin S, van Kesteren MT, Schoots VC, Cousijn H, Rijpkema M, Oostenveld R, Fernandez G (2011) Stress-related noradrenergic activity prompts largescale neural network reconfiguration. Science 334:1151-1153.

Hermans EJ, Henckens MJ, Joels M, Fernandez G (2014) Dynamic adaptation of large-scale brain networks in response to acute stressors. Trends Neurosci 37:304-314.

Ikemoto S (2007) Dopamine reward circuitry: two projection systems from the ventral midbrain to the nucleus accumbens-olfactory tubercle complex. Brain Res Rev 56:27-78.

Joels M, Fernandez G, Roozendaal B (2011) Stress and emotional memory: a matter of timing. Trends Cogn Sci 15:280-288.

Kalivas PW, Duffy P (1995) Selective activation of dopamine transmission in the shell of the nucleus accumbens by stress. Brain Res 675:325-328.

Keiflin R, Pribut HJ, Shah NB, Janak PH (2019) Ventral tegmental dopamine neurons participate in reward identity predictions. Curr Biol 29:93-103.e3.

Kelley AE (2004) Ventral striatal control of appetitive motivation: role in ingestive behavior and reward-related learning. Neurosci Biobehav Rev 27:765-776

Ko D, Wanat MJ (2016) Phasic dopamine transmission reflects initiation vigor and exerted effort in an action- and region-specific manner. J Neurosci 36:2202-2211.

Lak A, Stauffer WR, Schultz W (2014) Dopamine prediction error responses integrate subjective value from different reward dimensions. Proc Natl Acad Sci U S A 111:2343-2348.

Lammel S, Ion DI, Roeper J, Malenka RC (2011) Projection-specific modulation of dopamine neuron synapses by aversive and rewarding stimuli. Neuron 70:855-862.

Lee K, Claar LD, Hachisuka A, Bakhurin KI, Nguyen J, Trott JM, Gill JL, Masmanidis SC (2020) Temporally restricted dopaminergic control of reward-conditioned movements. Nat Neurosci 23:209-216.

Mackintosh NJ (1975) A theory of attention: variations in the associability of stimuli with reinforcement. Psychol Rev 82:276-298.

Montagud-Romero S, Aguilar MA, Maldonado C, Manzanedo C, Miñarro J, Rodríguez-Arias M (2015) Acute social defeat stress increases the conditioned rewarding effects of cocaine in adult but not in adolescent mice. Pharmacol Biochem Behav 135:1-12.

Natsubori A, Tsutsui-Kimura I, Nishida H, Bouchekioua Y, Sekiya H, Uchigashima M, Watanabe M, de Kerchove d'Exaerde A, Mimura M, Takata N, Tanaka KF (2017) Ventrolateral striatal medium spiny neurons positively regulate food-incentive, goal-directed behavior independently of D1 and D2 selectivity. J Neurosci 37:2723-2733.

Nawijn L, van Zuiden M, Frijling JL, Koch SB, Veltman DJ, Olff M (2015) Reward functioning in PTSD: a systematic review exploring the mechanisms underlying anhedonia. Neurosci Biobehav Rev 51:189-204.

Nicola SM (2010) The flexible approach hypothesis: unification of effort and cue-responding hypotheses for the role of nucleus accumbens dopamine in the activation of reward-seeking behavior. J Neurosci 30:16585-16600.

Oleson EB, Gentry RN, Chioma VC, Cheer JF (2012) Subsecond dopamine release in the nucleus accumbens predicts conditioned punishment and its successful avoidance. J Neurosci 32:14804-14808.

Oliva I, Wanat MJ (2019) Operant costs modulate dopamine release to selfadministered cocaine. J Neurosci 39:1249-1260.

Papageorgiou GK, Baudonnat M, Cucca F, Walton ME (2016) Mesolimbic dopamine encodes prediction errors in a state-dependent manner. Cell Rep 15:221-228.

Paxinos G, Watson C (2004) The rat brain in stereotaxic coordinates: the new coronal set. London: Elsevier Science \& Technology.

Puglisi-Allegra S, Imperato A, Angelucci L, Cabib S (1991) Acute stress induces time-dependent responses in dopamine mesolimbic system. Brain Res 554:217-222.

Rau V, Fanselow MS (2009) Exposure to a stressor produces a long lasting enhancement of fear learning in rats. Stress 12:125-133.
Rescorla RA, Wagner AR (1972) A theory of Pavlovian conditioning: variations in the effectiveness of reinforcement and nonreinforcement. In: Classical conditioning II: current research and theory (Black $\mathrm{AH}$, Prokasy WF, eds), pp 64-99. New York: Appleton-Century-Crofts.

Saddoris MP, Cacciapaglia F, Wightman RM, Carelli RM (2015) Differential dopamine release dynamics in the nucleus accumbens core and shell reveal complementary signals for error prediction and incentive motivation. J Neurosci 35:11572-11582.

Sapolsky RM (2015) Stress and the brain: individual variability and the inverted-U. Nat Neurosci 18:1344-1346.

Saunders BT, Robinson TE (2012) The role of dopamine in the accumbens core in the expression of Pavlovian-conditioned responses. Eur J Neurosci 36:2521-2532

Saunders BT, Richard JM, Margolis EB, Janak PH (2018) Dopamine neurons create Pavlovian conditioned stimuli with circuit-defined motivational properties. Nat Neurosci 21:1072-1083.

Schwabe L (2017) Memory under stress: from single systems to network changes. Eur J Neurosci 45:478-489.

Schwabe L, Wolf OT, Oitzl MS (2010) Memory formation under stress: quantity and quality. Neurosci Biobehav Rev 34:584-591.

Seeley WW, Menon V, Schatzberg AF, Keller J, Glover GH, Kenna H, Reiss AL, Greicius MD (2007) Dissociable intrinsic connectivity networks for salience processing and executive control. J Neurosci 27:2349-2356.

Shors TJ (2001) Acute stress rapidly and persistently enhances memory formation in the male rat. Neurobiol Learn Mem 75:10-29.

Shors TJ, Weiss C, Thompson RF (1992) Stress-induced facilitation of classical conditioning. Science 257:537-539.

Steinberg EE, Keiflin R, Boivin JR, Witten IB, Deisseroth K, Janak PH (2013) A causal link between prediction errors, dopamine neurons and learning. Nat Neurosci 16:966-973.

Stelly CE, Haug GC, Fonzi KM, Garcia MA, Tritley SC, Magnon AP, Ramos MAP, Wanat MJ (2019) Pattern of dopamine signaling during aversive events predicts active avoidance learning. Proc Natl Acad Sci U S A 116:13641-13650

Stuber GD, Klanker M, de Ridder B, Bowers MS, Joosten RN, Feenstra MG, Bonci A (2008) Reward-predictive cues enhance excitatory synaptic strength onto midbrain dopamine neurons. Science 321:1690-1692.

Tidey JW, Miczek KA (1996) Social defeat stress selectively alters mesocorticolimbic dopamine release: an in vivo microdialysis study. Brain Res 721:140-149.

Tovar-Diaz J, Pomrenze MB, Kan R, Pahlavan B, Morikawa H (2018) Cooperative CRF and alpha1 adrenergic signaling in the VTA promotes NMDA plasticity and drives social stress enhancement of cocaine conditioning. Cell Rep 22:2756-2766.

Tsai HC, Zhang F, Adamantidis A, Stuber GD, Bonci A, de Lecea L, Deisseroth K (2009) Phasic firing in dopaminergic neurons is sufficient for behavioral conditioning. Science 324:1080-1084.

Tsutsui-Kimura I, Natsubori A, Mori M, Kobayashi K, Drew MR, de Kerchove d'Exaerde A, Mimura M, Tanaka KF (2017a) Distinct roles of ventromedial versus ventrolateral striatal medium spiny neurons in reward-oriented behavior. Curr Biol 27:3042-3048.e4.

Tsutsui-Kimura I, Takiue H, Yoshida K, Xu M, Yano R, Ohta H, Nishida H, Bouchekioua Y, Okano H, Uchigashima M, Watanabe M, Takata N, Drew MR, Sano H, Mimura M, Tanaka KF (2017b) Dysfunction of ventrolateral striatal dopamine receptor type 2-expressing medium spiny neurons impairs instrumental motivation. Nat Commun 8:14304.

Valenti O, Lodge DJ, Grace AA (2011) Aversive stimuli alter ventral tegmental area dopamine neuron activity via a common action in the ventral hippocampus. J Neurosci 31:4280-4289.

Wilson LM, Wilson JR, Dicara LV (1975) Facilitation of Pavlovian conditioned cardiodecelerations following preshock in immobilized rats. Physiol Behav 15:653-658.

Yang H, de Jong JW, Tak Y, Peck J, Bateup HS, Lammel S (2018) Nucleus accumbens subnuclei regulate motivated behavior via direct inhibition and disinhibition of VTA dopamine subpopulations. Neuron 97:434449.e4.

Yuan L, Dou YN, Sun YG (2019) Topography of reward and aversion encoding in the mesolimbic dopaminergic system. J Neurosci 39:6472-6481. 